\title{
DE EUFORIAS MUNDIALISTAS Y REIVINDICACIONES FEMINISTAS. EL ESPACIO PÚBLICO DEL PASEO DE LA REFORMA, CIUDAD DE MEXICO, EN 1986 Y 2019
}

Da euforia da copa do mundo e reinvindicações feministas.

O espaço público do Paseo de la Reforma, Cidade do México, em 1986 e 2019

World Cup euphoria and feminist vindications.

The public space of Paseo de la Reforma, Mexico City, in 1986 and 2019

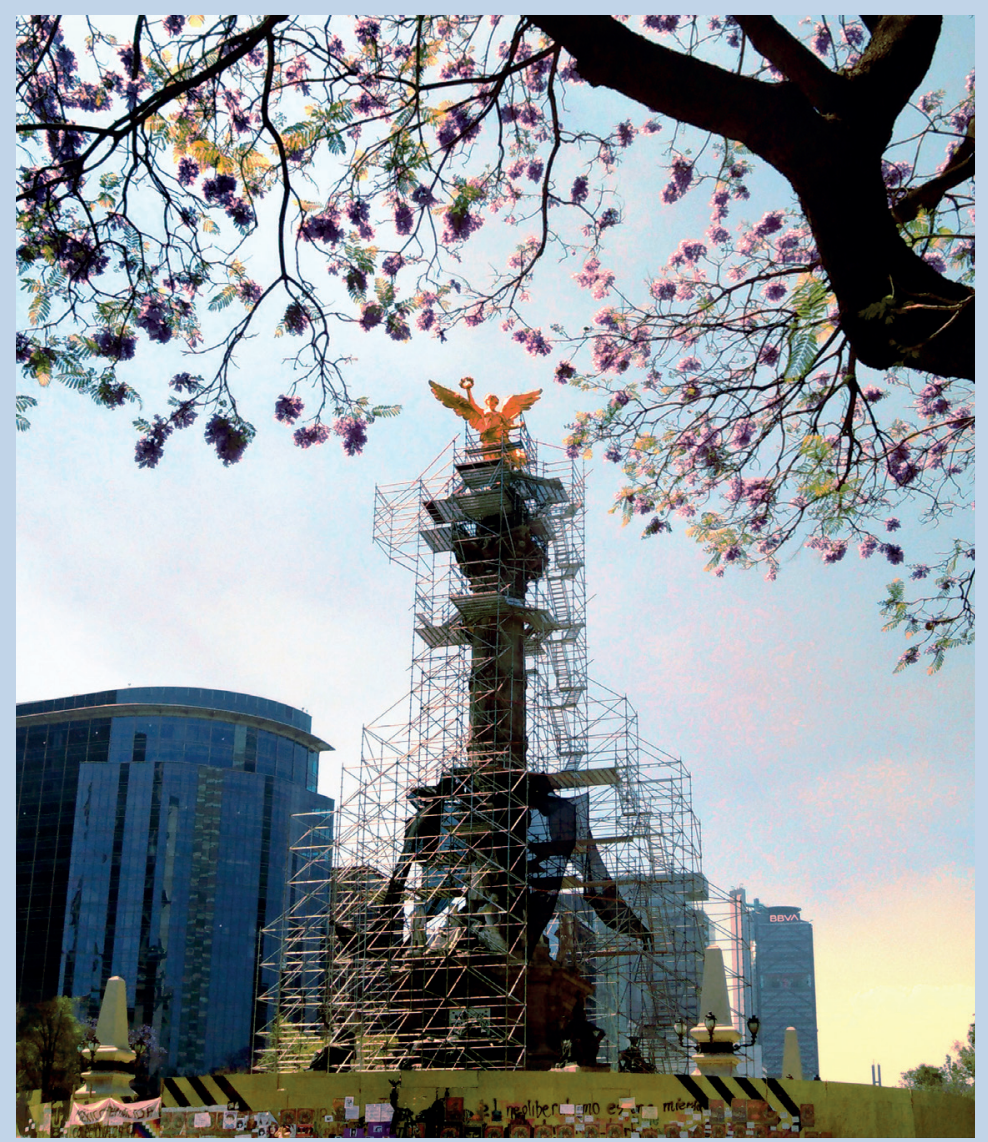

Vanessa Nagel Vega

Estancia posdoctoral, Centro de Investigaciones en Arquitectura, Urbanismo y Paisaje (CIAUP), Facultad de Arquitectura. Universidad Nacional Autónoma de México (UNAM). Ciudad de México. México. vanenagel7@gmail.com

https://orcid.org/0000-0002-7971-4000

Este articulo se realizo bajo la estancia posdoctoral, Centro de Investigaciones en Arquitectura, Urbanismo y Paisaje (CIAUP), Facultad de Arquitectura, UNAM.

Punto neurálgico de manifestaciones y reivindicaciones en la Ciudad de México: el Paseo de la

Reforma y su Ángel de la Independencia. Foto Vanessa Nagel,

1 de marzo de 2020 


\section{RESUMEN}

La ocupación masiva del emblemático Paseo de la Reforma, en la Ciudad de México, durante el Mundial de Fútbol 1986, con el país atravesando una fuerte crisis económica, fue un verdadero detonante para la diversificación de las manifestaciones en dicho espacio público. Asimismo, consolidó este escenario como el epicentro nacional de reivindicación de los derechos y demandas sociales de los mexicanos. En pleno siglo XXI, en medio de otra crisis, esta vez de violencia generalizada contra la mujer, el Paseo vuelve a resignificarse, abarcando a sus elementos más emblemáticos y tangibles, como el Ángel de la Independencia. Así, los monumentos se han vuelto los soportes de grafitis que luchan por trascender lo efímero al mantenerse sus reclamos vigentes. Este artículo propone una revisión histórica a los momentos más potentes de apropiación de este espacio público en 1986 y 2019 , tomando como principal fuente de consulta al periódico local La Jornada. La metodología planteada ofrece la reconstrucción de una crónica contada en tiempo real, verdadera contribución para entender cómo el estallido de la ocupación de las calles del año mundialista arraigó la apropiación del espacio público en los años subsiguientes. No cabe duda de que las euforias mundialistas ganaron para la sociedad la confianza de retomar las calles, coyuntura aprovechada desde entonces y vigente en las reivindicaciones feministas actuales.

Palabras Clave: Espacio público, Paseo de la Reforma, Mundial México 86, Ángel de la Independencia, feminismo

\section{RESUMO}

A ocupação massiva do emblemático Paseo de la Reforma, na Cidade do México, durante a Copa do Mundo de 1986, com o país passando por uma forte crise econômica, foi um verdadeiro gatilho para a diversificação das manifestações neste espaço público. Da mesma forma, consolidou este cenário como o epicentro nacional de reivindicação dos direitos e demandas sociais dos mexicanos. No século XXI, em meio a mais uma crise, desta vez de violência generalizada contra as mulheres, o Paseo volta a se resignificar, englobando seus elementos mais emblemáticos e tangíveis, como o Anjo da Independência. Assim, monumentos tornaram-se suportes de grafites que lutam para transcender o efêmero, mantendo suas reivindicações atuais. Este artigo propõe uma revisão histórica dos momentos mais poderosos de apropriação desse espaço público em 1986 e 2019, tomando como principal fonte de consulta o jornal local La Jornada. A metodologia proposta oferece a reconstrução de uma crônica contada em tempo real, uma verdadeira contribuição para a compreensão de como a eclosão da ocupação das ruas no ano da Copa do Mundo se enraizou na apropriação do espaço público nos anos seguintes. Não há dúvida de que a euforia da Copa do Mundo conquistou para a sociedade a confiança para voltar às ruas, situação que vem sendo explorada desde então e vigente nas atuais demandas feministas.

Palavras Chave: Espaço público, Paseo de la Reforma, Copa do Mundo México 86, Anjo da Independência, feminismo

\section{ABSTRACT}

The huge crowded occupation of the emblematic Paseo de la Reforma, in Mexico City, during the 1986 Soccer World Cup, with the country going through a severe economic crisis, was a real trigger for the diversification of the demonstrations in this public space. It consolidated this place as the national epicenter for the vindication of rights and social demands of the Mexicans. In the 21st century, in the midst of another crisis, this time the generalized violence against women, the Paseo is once again redefining itself, encompassing its most emblematic and tangible elements, like the Angel of Independence. In this way, monuments have become the canvas for graffiti that struggles to transcend the ephemeral by holding the current claims. This article proposes a historical review of the most powerful moments of appropriation of this public space in 1986 and 2019, using the local newspaper, La Jornada, as its main source of data collection. The proposed methodology offers the reconstruction of a narrative told in real time, a true contribution to understanding how the boom of the occupation of the streets in the World Cup year engrained the appropriation of public spaces in subsequent years. There is no doubt that the World Cup euphoria gave society the confidence to reclaim the streets, a situation that has been used since then and that is in force in the current feminist vindications demonstrations

Keywords: Public space, Paseo de la Reforma, Mexico '86 World Cup, Angel of Independence, feminism 
INTRODUCIÓN

UN DOMINGO EN EL PASEO DE LA REFORMA
A una semana del Día Internacional de la Mujer, la Ciudad de México vive una extraña calma. Con el paro nacional de mujeres en puerta, el 9 de marzo, y con cinco casos confirmados de Covid-19 en México, a las ocho de la mañana en punto se cerraban, como cada domingo, los carriles centrales del emblemático Paseo de la Reforma. Desde temprana hora y hasta las dos de la tarde, cientos de ciclistas, patinadores, corredores y andantes, solos o acompañados, transforman el espacio urbano de una de las arterias principales de la mega urbe de más de 20 millones de habitantes [Figura I]. Los mexicanos, acostumbrados a enfrentar estoicos los embates de la violencia generalizada, la desigualdad social y la incertidumbre de un futuro profesional, no sabemos si, un día o al siguiente, nos daremos de frente contra el muro de la realidad al no poder afrontar una situación de emergencia sanitaria que, todavía, parece irreal.

Por momentos, pareciera que la ciudad toma un respiro. La histórica avenida es transformada por la circulación a dos ruedas, el sudor y las endorfinas. La floración de las jacarandas —árbol de flores violetas, introducido en México desde Brasil por un jardinero japonés hace un siglo — termina de componer el cuadro típico de la adelantada primavera en la ciudad capital, vistiéndola de fiesta. Sin embargo, también son color morado las pintas que, en las vallas que "protegen" al icónico Ángel de la Independencia,

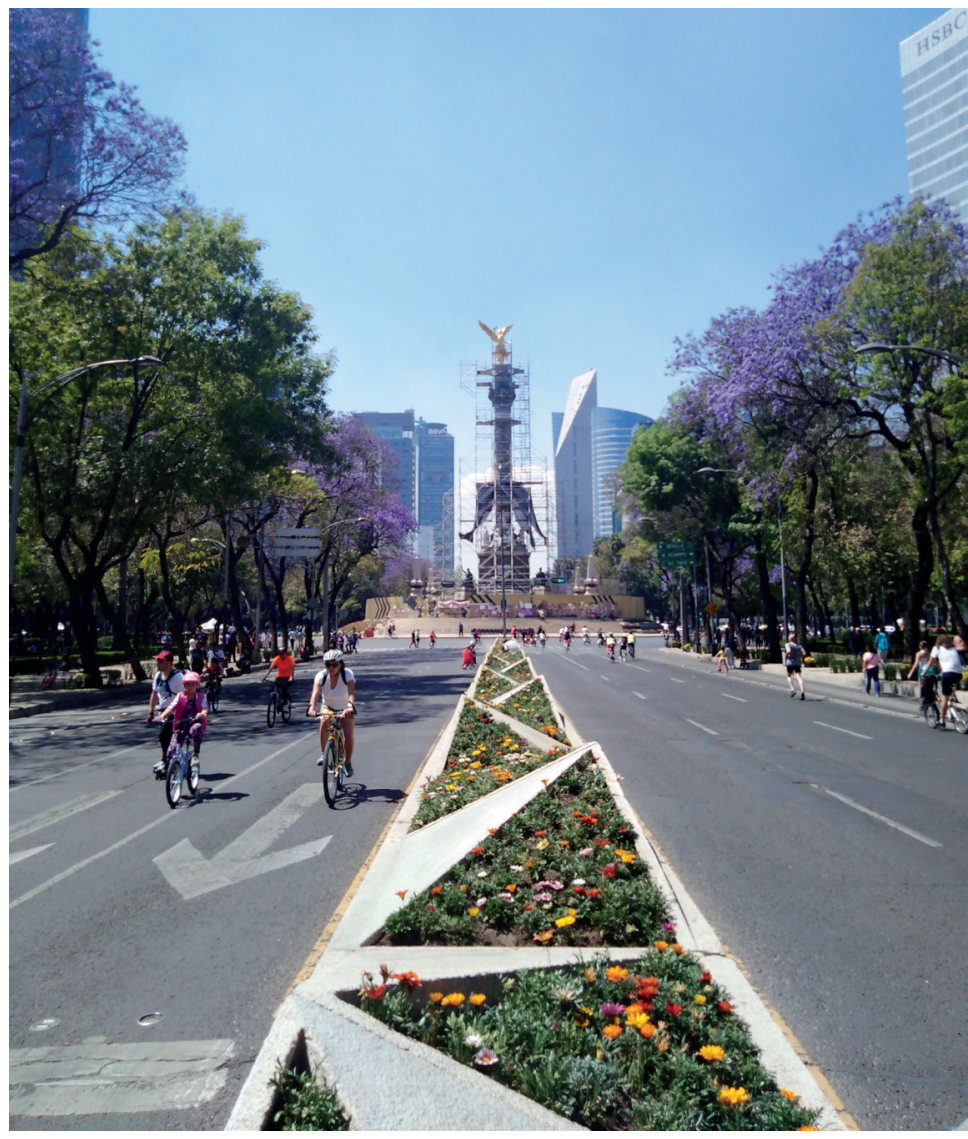

\author{
Figura 1 \\ Un domingo en el \\ Paseo de la Reforma, \\ Ciudad de México. \\ Fuente: Vanessa \\ Nagel Vega, Archivo
Vanessa Nagel, 1 de \\ marzo de 2020
}


reclaman "No más muertas" o "Qué vivan los cuerpos en resistencia en América Latina!' [Figura 2]. No faltan las teorías de la conspiración, una de ellas, la del "estado de emergencia" que paralice a la ciudad impidiendo las cercanas manifestaciones del 8 de marzo y obstaculizando las protestas feministas. Así, un hipotético letargo que frenara las relaciones que se forman entre los ciudadanos y su espacio público a partir del ejercicio de la protesta evitaría el diálogo entre el poder político y la sociedad.

Lo que se propone revisar aquí es cómo la ciudadanía ha replanteado y transformado su relación con el espacio público. Para este análisis se revisan algunos antecedentes de apropiación de dicho espacio en la Ciudad de México, en especial en el Paseo de la Reforma, desde sus primeras expresiones a principios del siglo $X X$ y con especial intensidad en 1968. El periodo de estudio se centra en el Mundial de México 86, que resultó en una verdadera conquista de las calles, en un momento de grave crisis económica nacional, y, en tiempos recientes, en el año 2019 y hasta el presente, caracterizado por una fuerte incidencia del movimiento feminista internacional en México.

Se parte de un escenario que es la ciudad, donde convergen grupos sociales complejos. Así, el sentido actual de lo público hace referencia a la vida social que se lleva a cabo fuera del dominio privado y a una gran

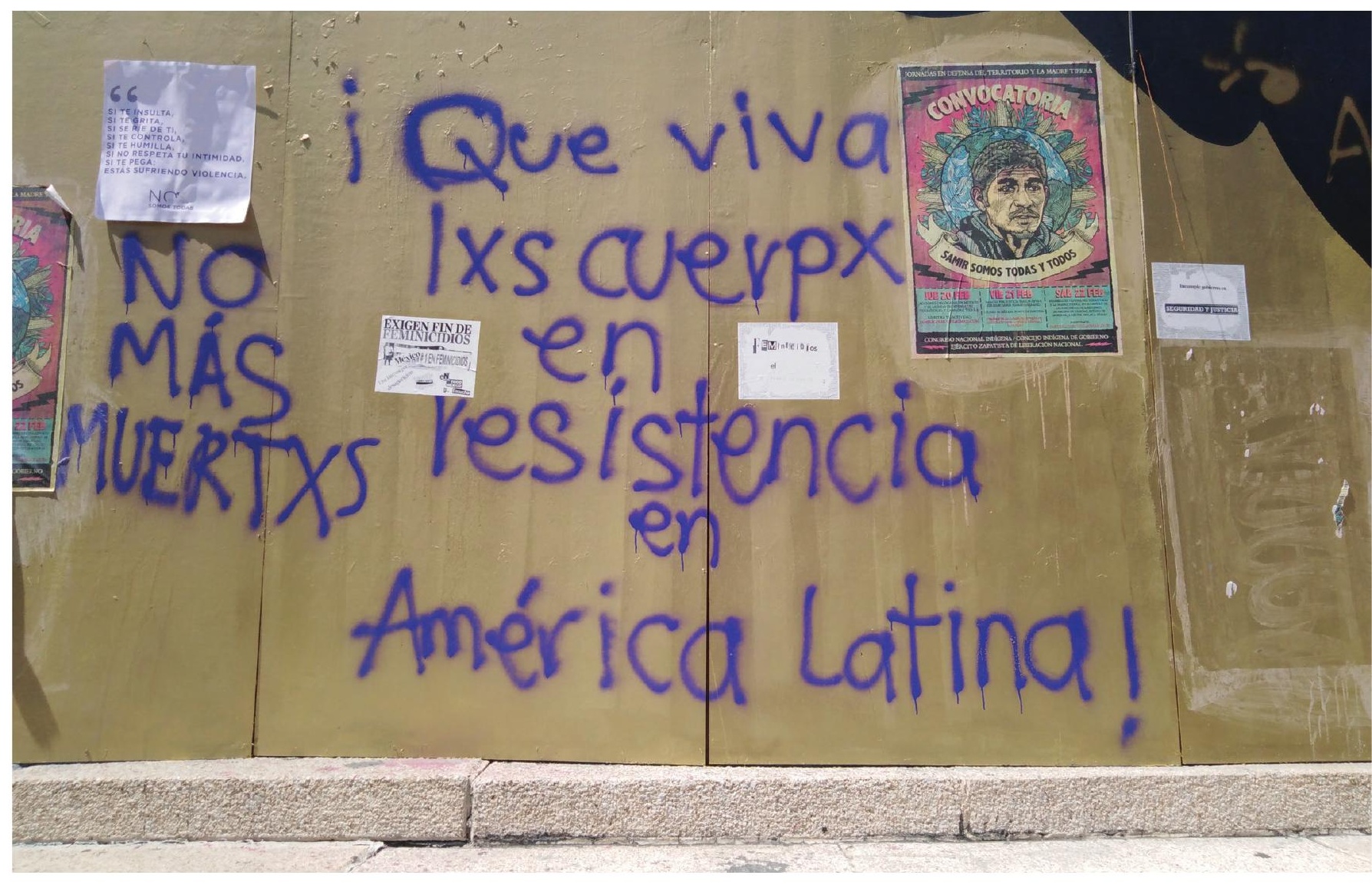


1 Fue El 24 de julio de 2020 el Congreso de la CDMX aprobó reformas al Código Penal que tipifican como delito las "terapias de conversión", por atentar contra el libre desarrollo de la personalidad e identidad sexual y de género de las personas de la ciudad. Este dictamen representa una victoria reciente para la lucha de la comunidad LGBTTTI.

\section{DEL SUEÑO IMPERIAL A LA CONQUISTA DE LA CALLE (1913-1968)}

2 El Segundo Imperio Mexicano, encabezado por Maximiliano de Habsburgo y Carlota de Bélgica se instauró después de la intervención francesa en 1863. Terminaría con el fusilamiento de Maximiliano, por órdenes del presidente de la República Benito Juárez, en 1867.

3 En febrero de 1913 se llevaría a cabo el golpe de estado al gobierno legítimo y democráticamente establecido del presidente Francisco I. Madero, líder inicial de la revolución quien derrocaría el largo régimen de Porfirio Díaz en 1911. El general Victoriano Huerta —el usurpadormantendría el poder escasos 18 meses, a lo que seguirían todavía varios años de luchas entre los distintos bandos.

4 El 5 de febrero de 1917 en la nueva Constitución —artículo 123- se reguló el derecho del trabajo. Sería hasta 1923 cuando se hace oficial el Día del Trabajo y se decreta el descanso obligatorio. diversidad de personas que conforman una población urbana heterogénea. Es en los espacios públicos de la ciudad donde se llevan a cabo las prácticas más visibles y polémicas de la ciudadanía, esto es, las reivindicaciones de sus derechos políticos, sociales, culturales y urbanos (Ramírez, 2015). El fin de estas reivindicaciones es transformar los marcos legales vigentes. Es un proceso lento, pero no deja de anotarse algunos triunfos. ${ }^{1}$

El espacio público del Paseo de la Reforma en las inmediaciones del Ángel de la Independencia se considera aquí, más que un lugar de encuentro, un espacio de identificación y de lucha por la reivindicación de los derechos sociales, mismos que, con el paso de las décadas, se han diversificado hasta alcanzar las recientes demandas feministas. Estos reclamos, al llegar a la opinión pública, han sido constantemente registrados en la prensa diaria. Por tal motivo, esta investigación se sustenta en la consulta rigurosa de medios impresos periódicos, labor realizada en la Hemeroteca Nacional, en la Universidad Nacional Autónoma de México. La reconstrucción de las manifestaciones en el espacio público de la Ciudad de México nos permite aproximarnos a una de las arterias principales de la capital del país desde la perspectiva de las demandas sociales más potentes de los últimos años.

El efímero sueño imperial de los Habsburgo en México² nos legó una de las avenidas más emblemáticas de la capital del país. Primero conocida como Paseo de la Emperatriz — en el que por decreto del Emperador en el paseo sólo se permitía la circulación de carruajes de los emperadores y su séquito- después nombrado Paseo Degollado, en honor a un general incondicional de Benito Juárez, quien reestablecería la República en 1867 y, a partir del siglo XX, como Paseo de la Reforma. Centro neurálgico de manifestaciones, celebraciones populares, desfiles y actividades cívicas, el Paseo se reconoce por su monumento icónico, una victoria alada conocida popularmente como Ángel de la Independencia, por ser ésta una columna erigida con motivo de las celebraciones del primer centenario de la Independencia en 1910.

La segunda década del siglo XX en México, después de más de treinta años de dictadura con Porfirio Díaz, fue un periodo sobre todo convulso. Entre movimientos armados que se generalizaron en casi todo el territorio, traiciones entre facciones revolucionarias, golpes de estado y negociaciones, en $1913^{3}$ se celebraría, por primera vez en el país, el Día del Trabajo (El Imparcial, 1913a). Ese año se buscaba el apoyo obrero para legitimar al régimen golpista y —al menos eso se esperaba — reestablecer la paz social. El reclamo por mejores condiciones laborales —incremento salarial, jornada de ocho horas y seguro de accidentes — ${ }^{4}$ en un país sin vida democrática interesa, sobre todo, por haber reunido a veinticinco mil obreros en torno al Hemiciclo a Juárez en la Alameda Central. La apropiación, sin precedentes, del espacio:" "fue verdaderamente imponente por la inmensa muchedumbre que se agolpaba al derredor del monumento. Pocas veces se ha congregado tal cantidad de gente en un paraje público" (El Imparcial, 19|3b).

Las décadas posrevolucionarias serían de consolidación del gobierno 
institucionalizado, dirigido a impulsar la economía, la industrialización del país, la alfabetización de las zonas rurales y la educación superior de las clases medias urbanas. Los gobiernos —en realidad el mismo partido reelegido una y otra vez, impidiendo una verdadera transición democrática y formando, de cierto modo, una nueva dictadura- también instauró numerosos programas sociales.

En varias décadas de crecimiento económico sostenido, en especial en el periodo llamado "milagro mexicano" (1946-1970), los reclamos sociales sí estuvieron presentes, pero siempre se habían desarticulado fácilmente debido a que

Las demandas que habían enfrentado los gobiernos posrevolucionarios habían emergido siempre de luchas sociales y gremiales de algún sector determinado: los campesinos, los mineros, los ferrocarrileros, los maestros, los médicos, a los que el Estado siempre había podido aislar y reprimir, sin que el costo político de estas acciones cuestionara mayormente su ejercicio del poder (Garavito, 2018)

El momento decisivo en el uso del espacio público en la Ciudad de México se da en el verano de 1968. Semanas antes de la masacre perpetrada en la Plaza de las Tres Culturas de Tlatelolco — un 2 de octubre - el movimiento estudiantil, que había llevado a una huelga indefinida a las principales universidades de la capital, era una fiesta. Por primera vez en la historia se expresaba una reivindicación ciudadana por la libertad. Las demandas eran universales, no sectoriales o gremiales. Debido a su inclusión generalizada, la marcha del 27 de agosto de 1968 convocó a tomar la calle, lo que hicieron alrededor de 400 mil personas que marcharon pacíficamente, diríase incluso que festivamente, por el Paseo de la Reforma [Figura 3]. Fue

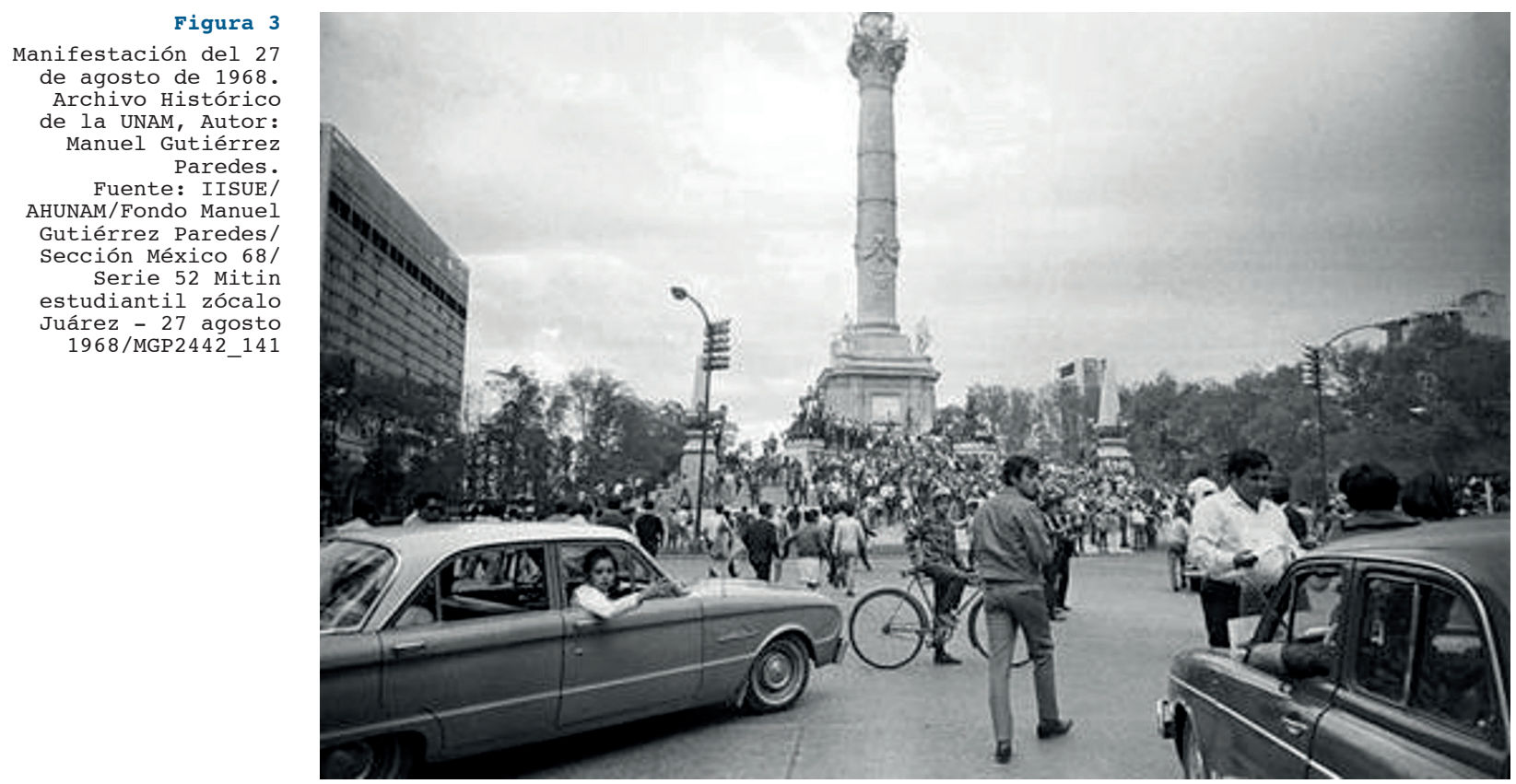

AS / Vol. 38. No58 / JULIO 2020 // ISSN impresa 071 6-2677 / ISSN digital 0719-6466 
5 La otra marcha emblemática del movimiento estudiantil de 1968 en México fue la del silencio, el 13 de septiembre.

6 La marcha por la memoria del 2 de octubre de 1968 se mantiene viva y se realiza en la Ciudad de México cada año en esa fecha, como una reivindicación por la libertad ganada ese año y cobrada muy caro - con la sangre de cientos de personas-por el régimen represor del presidente Gustavo Díaz Ordaz.

\section{PASIONES FUTBOLÍSTICAS (1986)}

7 Memorable es también el episodio ahora conocido como "El Halconazo", que tuvo lugar el 10 de junio de 1971, un jueves de Corpus Christi, en que una manifestación estudiantil fue reprimida por un grupo paramilitar al servicio del Estado.

Las muertes nunca se aclararon y los responsables nunca fueron llevados ante la justicia.

8 Coincidentemente, un nuevo sismo, también de consecuencias asoladoras para la capital del país, se registró, también, un 19 de septiembre, pero del año 2017.

9 La decisión de la FIFA de dar la sede a México se dio hasta mayo de 1983. Hacia finales de 1982 Colombia, país asignado para la sede del evento, renunció, ya que no alcanzaría a cumplir con los requisitos de infraestructura. México, en principio, contaba con suficientes estadios y experiencia en la organización de eventos internacionales (XIX Olimpiada de 1968 y Mundial de 1970). una de las manifestaciones más potentes de todas las de ese corto verano. ${ }^{5}$

A unos días de la inauguración de la XIX Olimpiada en México —en la simbólica fecha del 12 de octubre - no sólo no hubo diálogo público, sino que tuvo lugar una de las represiones más sangrientas en la historia reciente del país. La tarde del 2 de octubre, en el mitin de Tlatelolco, "diez mil personas estaban en la plaza; decenas, quizá cientos, murieron; mil fueron detenidos; cientos permanecieron en la cárcel más de dos años. [Así] el gobierno acabó con el movimiento, pero al mismo tiempo lo hizo inolvidable" (Pérez, 2009). ${ }^{6}$

Si bien las calles no quedaron desiertas después del 2 de octubre, y si bien tampoco se acabó la represión,? después del 68 y el 7l hubo un cierto —obligado_ recogimiento de la población civil. El crecimiento económico sostenido de México que había caracterizado las décadas anteriores empezó a sufrir violentas crisis, devaluaciones, endeudamiento exterior, inflación, recesión, con especial fuerza en 1976, 1982 y 1986.

Para agravar la crisis de mediados de los ochenta, un sismo de magnitud 8,1 —el 19 de septiembre- ${ }^{8}$ devastó a la Ciudad de México, colapsaron cientos de edificios y, aunque nunca se supo el número preciso de víctimas mortales, — aunque se habla de miles — dejó a la ciudad, por años, en estado de emergencia y con incontables damnificados que perdieron su vivienda o que no pudieron regresar a ella por los daños estructurales y el riesgo implícito del colapso. En medio de esa crisis estaba en puerta el evento masivo del Mundial de Fútbol México 86.9 Aún con la ciudad en ruinas, el evento siguió su curso, dando pie a la más increíble reapropiación del espacio público como nunca se había visto en la historia del país.

México en 1986 era no sólo un país con su capital devastada por el sismo de septiembre de 1985, sino también un país golpeado por la crisis económica generada, especialmente, por la caída mundial del precio del petróleo, por el endeudamiento con el exterior, la devaluación del peso contra el dólar, con una tasa de inflación en aumento, incremento de desempleo — ese año fue memorable el cierre de la Fundidora de Monterrey, que dejó sin trabajo a miles de obreros de esa ciudad industrial del noreste del país. Con todo, el 3 I de mayo, el presidente Miguel de la Madrid Hurtado inauguraba en el Estadio Azteca la decimotercera edición de la Copa Mundial de Fútbol. El primer mandatario sería recibido por los miles de aficionados con animadversión. Los medios de la época lo calificaron de una "respuesta visceral y espontánea ante la personificación de las vicisitudes por las que hoy transcurre la vida de la inmensa mayoría de los mexicanos" (La Jornada, 1986a). El editorial del matutino confirmaba los "signos de una reacción inarticulada antiautoridad". La sociedad, se decía, estaba "deseosa de canales para expresar sus inquietudes y reivindicaciones" (La Jornada, 1986b).

El mismo día de la inauguración, y de manera espontánea, miles de capitalinos ocuparon por horas el Paseo de la Reforma en las inmediaciones del Ángel de la Independencia. Los cronistas de la época 
consignaron "un grito como retenido por mucho tiempo que estallaba borracho. ¡México, México!' (Velázquez, 1986). Hacia las 23 horas más de 10 mil personas habrían tomado el monumento a la Independencia. Entre los que ondeaban banderas y los que decidían montarse en los hombros de la estatua de Miguel Hidalgo —uno de los héroes patrios - se percibía enojo, molestia.

El fenómeno social no pasó desapercibido para los analistas. De inmediato, en la prensa, se empezaron a aventurar hipótesis sobre el fútbol como la nueva identidad del mexicano (Peralta, 1986). Y, como en cada justa mundialista, el fútbol de México se proyectaba "a la cumbre del Olimpo, como manifestación triunfadora que responde a los enunciados obligatorios de la publicidad enajenante" (Cheix, 1986). Las estadísticas estaban en contra de la selección nacional. Para ese año del 86, en 24 juegos mundialistas sólo se habían obtenido tres victorias, cuatro empates y diecisiete derrotas. Los expertos, que no se alimentaban de falsas ilusiones, sólo esperaban un buen partido.

La sorpresa fue el triunfo de México contra los diablos rojos de Bélgica 2 a I (La Jornada, 1986c). No sólo la alegría se desbordó en la calle, también los desórdenes y el vandalismo invadirín la ciudad (Avilés y Velázquez, 1986). La reacción popular, entendida como una válvula de escape ante la crisis económica, como un paliativo temporal que duraría un mes, o menos — hasta la descalificación de la selección nacional— era perfectamente previsible. De pronto, la obsesión contraria a toda razón, la violencia, la toma de las calles, no tenía nada que ver con el campeonato mundial, pero era "como si en él se jugara el honor y el destino de México" (La Jornada, 1986d). Los excesos alcanzarían a los monumentos patrios, ya que

Como resultados del fin de fiesta, al cura Miguel Hidalgo, en el monumento a la Independencia le mutilaron los dedos de mármol y la punta de su bandera fue quebrada; fue robada la espada de Vicente Guerrero y el libro de visitantes distinguidos desapareció; la lámpara del Altar de la Patria fue rota; la puerta de entrada al monumento fue violada y alguien intentó infructuosamente abrir las urnas donde descansan las cenizas de los próceres de la Independencia" (La Jornada, 1986e).

El desahogo social era justificado. Además de las noticias relacionadas con el transcurrir del Mundial, las primeras planas en esos días de junio de 1986 se llenaban con las de la temida moratoria, esto es, la suspensión de pagos al Fondo Monetario Internacional por la eterna deuda externa mexicana (Jacob, 1986; Galaz, 1986; Ureña, 1986). Así, la escritora Guadalupe Loaeza, poniendo voz al Ángel, diría de los miles de aficionados que ocuparon y mutilaron el monumento, que "no estaban celebrando ningún triunfo, sino que estaban inconscientemente preparándose para una derrota sumamente grave y que no tiene nada que ver con el fútbol" (Loaeza, 1986).

El 7 de junio, en su segundo partido, México empataría con Paraguay 
I - I. El Departamento del Distrito Federal —ahora Ciudad de Méxicopreviendo los desmanes del partido anterior, organizaría los festejos en determinados puntos de la capital, con templetes, música y venta de banderitas y la mascota del mundial - "Pique"- en todas sus presentaciones. Un día antes se había declarado ley seca, sin que con esto se evitara el consumo desmedido de alcohol en la vía pública. Con el empate, México estaba en el umbral de la clasificación a los octavos de final.

Es notable que en la prensa se hablara de este acto cívico - aunque desmedido - de apoderarse de la calle como una verdadera revolución. "Desde el 68 no salíamos, así, a la calle para estar juntos," diría el arquitecto y urbanista Manuel Larrosa (1986). El II de junio de 1986, en el Estadio Azteca, clasificando a los octavos de final, México ganaba a Irak I-0. Ese día, en la primera plana de La Jornada, se leía que México negociaba para ajustar los pagos de su deuda externa y que no había perspectivas inmediatas para superar la crisis en ese sexenio ( $L a$ Jornada, 1986f). La noticia distaba mucho de ser únicamente de interés nacional, el presidente de Estados Unidos, Ronald Reagan, declaraba el peligro de que México suspendiera los pagos de su deuda (La Jornada, 1986g). En este contexto
Las fiestas y la algarabía especial que se experimentan en las ca- lles y plazas públicas a propósito del evento futbolero muestran que estamos necesitados en la ciudad de México de instancias de relación humana, de lugares públicos de encuentro natural. (...) Y la gente las necesita. (...) El Mundial ha permitido la ex- presión de esa necesidad social profunda" (Paoli, 1986).

La inmediatez del triunfo era lo que importaba. No faltaron las críticas a esa falsa identidad nacional, pero no permearon — no podrían - en el ánimo de la población urgida no sólo de los espacios apropiados para el desahogo, sino de las excusas necesarias para la amnesia colectiva. El fútbol, al decir de Heberto Castillo — diputado y dirigente del Partido Mexicano de los Trabajadores - era "una droga muy cara que sólo dura un mes", pues, como suele ocurrir en estos casos, no se había hecho pública, hasta ese momento, la información sobre "los miles de millones que se han gastado en la selección mexicana (Peralta, 1986b)."

Los millones de pesos gastados en el Tri — como se conoce popularmente a la selección mexicana - serían redituables por lo menos hasta los octavos de final, con el triunfo de México sobre Bulgaria 2-0. Si hasta la primera ronda eliminatoria habín sido decenas de miles los aficionados que tomaron las calles, el triunfo en octavos llevó a más de un millón de personas a ocupar el espacio público, en una insólita conquista urbana [Figura 4]. Sólo en tomo al Ángel de la Independencia se conglomeraron alrededor de I 50 mil personas — 50\% más que la capacidad del Coloso de Santa Úrsula, como se conoce al Estadio Azteca—; los festejos continuaron hasta la madrugada del día siguiente (Meneses y Salanueva, 1986).

El fin de la fiesta futbolera tuvo lugar en Monterrey, Nuevo León, el 
sábado 21 de junio de 1986. En cuartos de final México perdería contra Alemania I-4 en penaltis. A pesar de la lluvia que se registró en la capital, cientos de personas se reunieron en el Zócalo capitalino (La Jornada, 1986h). El verdadero balde de agua fría no sería la persistente lluvia de esa tarde, sino la noticia del 23 de junio, en primera plana: "México atraviesa la crisis más profunda en los últimos 50 años" (Galaz, 1986c). El 29 de junio de 1986, con Diego Armando Maradona como el héroe indiscutible del Mundial, en el Estadio Azteca, Argentina arrebataría el triunfo a Alemania. El 30 de junio tocaría despertar sin la expectativa del Mundial y sin pretexto para seguir la fiesta, tocaría despertar a la cruda realidad.
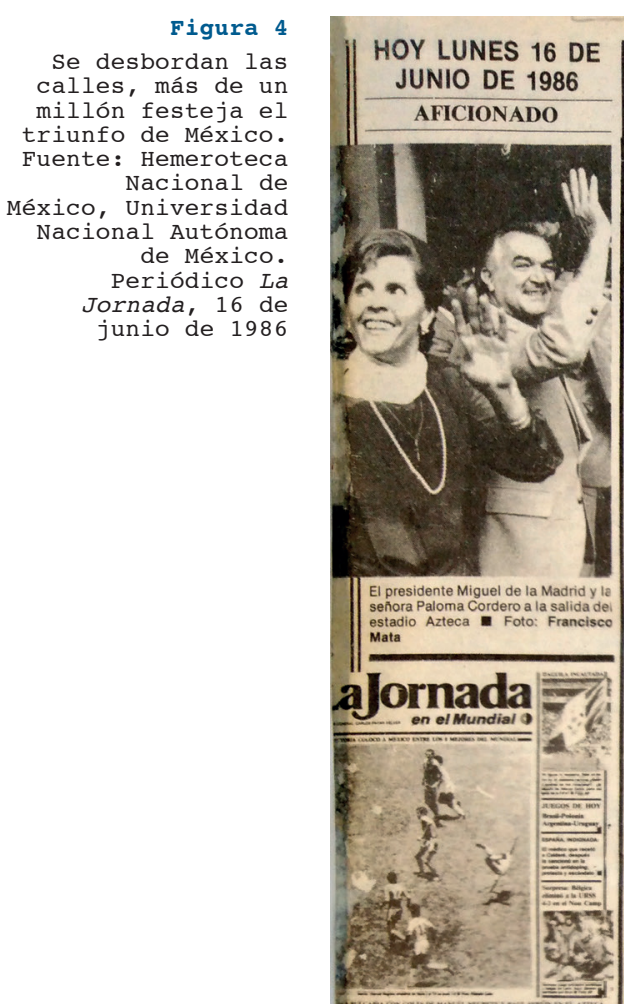

ME-XI-CO... 2-0!!

Cesaron a directivos en Chernobil

México 2, Bulgaria 0 Bélgica 4, URSS 3

Plaza puBLICA - Impacto, nueva direccion -Miguel Angel Granados Chapa
- Ei nummero 18994 de la revista Im.
pacto, fechado el 19 de junio, pero

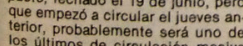
los úitimos de circulaciación masiv
del semanario fundado en 1949 del semanario fundado en 1949 por
don Regino Hernández Lergo. Ur
decisión decisión nel connsejo de ardininistra
cion, en asamblea celebrada el 9 de

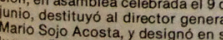
ugar a Erasmo Fernández de Men giro completo en el tono de la revis tay por ende una
tavor del público

Cien pesos

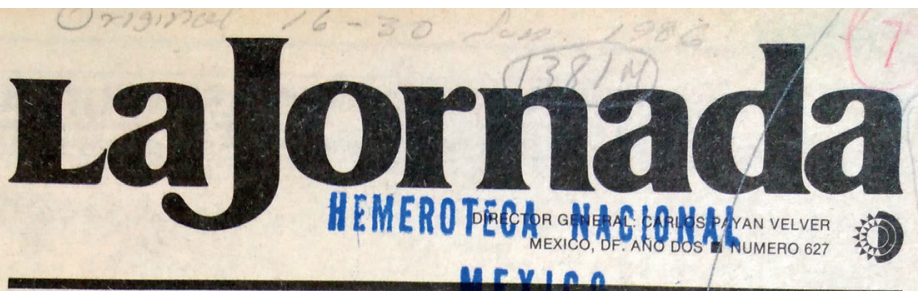

CELEBRACION MULTITUDINARIA EN LA CAPTITAL DEL PAIS

Más de un millón de personas festejó en las calles el triunfo de México

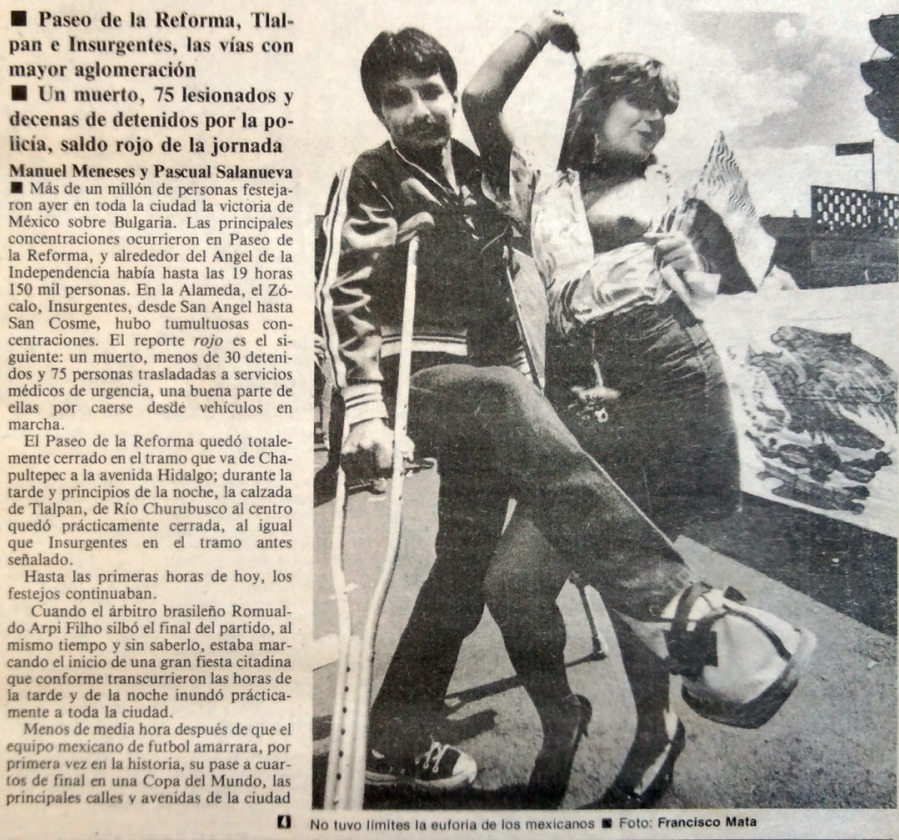

FIESTA TRICOLOR ENSORDECIDA POR LOS BOCINAZOS

La euforia convirtió al DF en un gran estadio

- Miguel Angel Velázquez, Jaime Avilés, Luis Miguel Aguilar, Hermann Bellinghausen,

- Los milagros del santo chile sacudieron a los restejos hogareños en el sur por cortesía de la aficionados al futbol

aficionados al futbol -Paren esto!, grito angustiado sofocado por La celebración

la multitud en un reventódromo
La barata búlgara ofreció a mitad de precio el no la policía
Argumento: hay que dispersarlos "para dar La barata búlgara ofreció a mitad de precio el argumento: hay que dispé
pase a la siguiente ronda

- "Sacaremos al Abuelo de la banca / y echare- El griterío abandonó el Azteca y comenzó a mos a Alemania a la barranca" ganar espacios en la urbe

- El representativo pasó de nueva cuenta la Decenas de grúas y patrullas enfriaron rápido prueba del orgullo nacional el ánimo en Tlalpan y Periférico

Insurgentes, apastelamiento de autos y jóve- Río estrepitoso de automóviles cruzan la nes de clase media para arriba ciudad hasta entrada la noche 


\section{REIVINDICACIONES FEMINISTAS DEL SIGLO XXI}

No cabe duda de que la ocupación de la calle durante el Mundial de México 86 fue una conquista duradera. En la segunda década del siglo XXl, el número de manifestaciones en la capital del país alcanza cifras inauditas. Durante 2017 se llevaron a cabo, al menos, 2 mil 436 marchas y 58 plantones. El Paseo de la Reforma "fue la única vialidad que permaneció ocupada por manifestantes en los 12 meses; en ésta se registraron 706 marchas y plantones" (Hernández, 2018). Esto nos habla de una cotidianeidad que dista mucho de representar casos aislados de ocupación de la calle. Así, una de las vialidades más emblemáticas de la ciudad, literalmente, dobla turno para atender el sinnúmero de demandas que, día con día, se expresan en su espacio público. Sin contar, claro está, los eventos deportivos o los desfiles conmemorativos que, asimismo, caben en ese contenedor polivalente que es el Paseo de la Reforma.

En 2019, en el ámbito político en México, pareciera que casi se ha alcanzado la paridad de género en cuanto a representantes legisladores en las Cámaras de Senadores y Diputados. Esto sitúa al país como uno de los estados con mayor porcentaje de legisladoras en el mundo. Nunca ha habido en México tantas mujeres en la política y ocupando cargos públicos, como ahora. Sin embargo, a decir de los expertos, los derechos de las mujeres están en el papel, no en la realidad del día a día, lo que sigue marcando la consabida desigualdad de género (La Jornada, 2019a). El malestar social por la desigualdad en el ámbito laboral se ve exponencialmente incrementado por la violencia de género y la imparable ola de feminicidios que asola al país. Las manifestaciones en demanda de derechos universales como el aborto legal y seguro y el alto a las desapariciones tampoco es reciente. Una de las marchas más potentes en este sentido se registró con la convocatoria de la primera Movilización Nacional contra la Violencia Machista, con acciones en al menos 25 ciudades mexicanas y con una participación masiva —más de diez mil mujeres, según organizadoras - en la Ciudad de México, el 24 de abril de 2016 (Juárez, 2016).

Con motivo del Día Internacional de la Mujer, en México y en el mundo, las mujeres reivindicaron demandas históricas (La Jornada,, $2019 b)$ [Figura 5]. En nuestro país, las dos demandas feministas principales fueron el rechazo a la violencia contra las mujeres, caracterizada por prendas de color morado, y el derecho a decidir sobre sus cuerpos, que ha dado la vuelta al mundo por su imagen de pañuelos verdes (Xantomila, 2019).

Si, como se expresó al principio de este análisis, las relaciones que se establecen entre el ciudadano y el espacio público a partir del ejercicio de la protesta promueven el diálogo entre el poder político y la sociedad, cabe preguntarse si, en el futuro inmediato, tendrán repercusión — positiva — las constantes manifestaciones que claman un alto a la violencia en un país que ya no puede ocultar las estadísticas: en promedio, diez mujeres son asesinadas al día por su condición de 


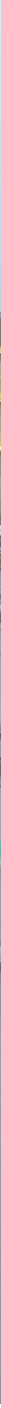

Figura 5

Manifestación del Día Internacional de la Mujer entrando al zócalo de la Ciudad de Fuente: Vanessa Nagel Vega, Archivo Vanessa Nagel, 8 de marzo de 2019 
género. De igual manera que en el año 1986 la sociedad mexicana se desahogó - temporalmente- de los embates de la crisis económica bajo el pretexto del Mundial, en 2019, el hartazgo de un sistema judicial que culpa a las víctimas de violencia sexual, y con índices inauditos de acosos, violaciones y asesinatos, transformaron en furia una protesta pacífica (Bravo, 2019). Una turba frenética, a su paso, iría vandalizando infraestructura del transporte público y monumentos, abriéndose paso hacia el icónico Ángel, plasmando allí las pintas que ocuparon las primeras planas de los diarios y que se volvieron tendencia en las redes sociales [Figura 6]. La política actual es la de sortear la represión, por lo que se evitó el uso de la fuerza pública para frenar el vandalismo. Al tiempo que se condenaban las agresiones a periodistas y el daño a la infraestructura urbana y monumentos, se reconocía, también, el legítimo reclamo feminista. Las imágenes sobre la furia desatada son también las del enojo ante las violaciones y asesinatos de mujeres, así como por la nula procuración de justicia y la impunidad hacia los agresores. Las pancartas son sintomáticas del estado de ánimo de las mexicanas: "Si algún día no vuelvo a casa no prendas velas, prende barricadas" o "Si me matan, si me violan, si me desaparecen, idestrúyelo todo!" (La Jornada, 2019c).

La mañana del sábado 17 de agosto el emblemático Ángel desplegaba sus alas con la carga emocional de las demandas femi-

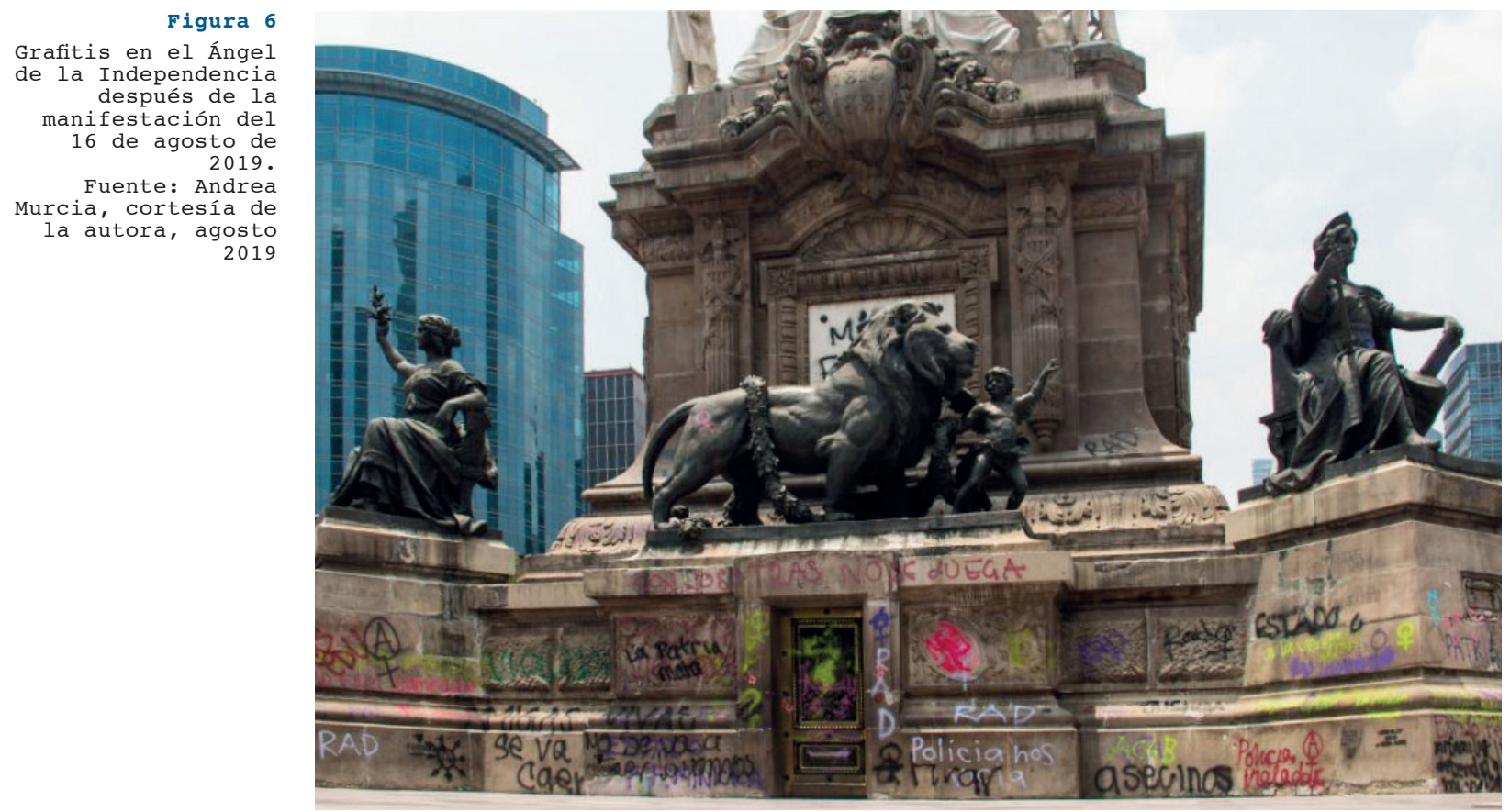

AS / Vol. 38. No58 / JULIO 2020 // ISSN impresa 07 16-2677 / ISSN digital 0719-6466 
nistas, al tiempo que un ejército de trabajadores de la Ciudad de México se disponía a borrar las pintas. Una enorme tapia rodeó la columna. De inmediato, la Secretaría de Cultura de la ciudad informó que se realizaría un dictamen sobre las afectaciones al patrimonio para iniciar los trabajos de restauración (La Jornada, 2019d). Si en un primer momento se pensó en recuperar a la brevedad el estado original del inmueble (González, 2019), muy pronto quedó en evidencia la importancia de mantener los grafitis como un recordatorio de la violencia en el país, al tiempo que garantizar la preservación de la memoria histórica de una expresión que va más allá del simple arte urbano, como lo manifestó el grupo independiente Restauradoras con Glitter (Código. Arte - Arquitectura - Diseño, 2019). Por primera vez, las expresiones de las marchas trascienden lo efímero.

Es innegable que las pintas al Ángel - por su impacto visual y su inmediata circulación en redes sociales y en la prensa tradicional- sacudieron a más de una conciencia aletargada. También, desempolvaron el presupuesto asignado —y no ejercido todavíaproveniente del Fondo de Desastres Naturales (Fonden) para atender los daños que la columna del Ángel de la Independencia sufrió durante los sismos de septiembre de 2017 (Mateos-Vega). El titular de la Secretaría de Cultura de la Ciudad de México anunciaría que aún no se había estimado el costo de la restauración, pero, paradójicamente, salió a la luz pública lo del presupuesto no ejercido. Se dijo, se seguía trabajando en el registro fotográfico de las pintas, como una acción para garantizar el derecho a la memoria en la Ciudad de México. Lo cierto es que la prontitud con que se tapió el monumento y se cubrió con un enorme andamio, bajo la excusa de la evaluación estructural, a dos años del sismo y apenas un par de semanas después de la protesta feminista (Vargas, 2019) parece corresponder más a una intención soslayada de invisibilizar al monumento [Figura 7].

Si en México, en muchos sentidos, el modus operandi ha sido volver invisible la violencia, los desaparecidos, la pobreza extrema, $y$, ahora, hasta los monumentos, el movimiento feminista no ha decaído. Al contrario, parece tomar más fuerza cada día. El 25 de noviembre, Día Internacional de la Eliminación de la Violencia contra la Mujer, se realizaron en el mundo múltiples acciones y movilizaciones para hacer conciencia y combatir la atroz hostilidad que va de la discriminación laboral a la violación y del acoso al feminicidio (La Jornada, 2019). Nuestro país no fue la excepción. Una nueva marcha del Ángel al Zócalo se anticipó viva y enérgica para cambiar una realidad insostenible (Gómez, 2019). 


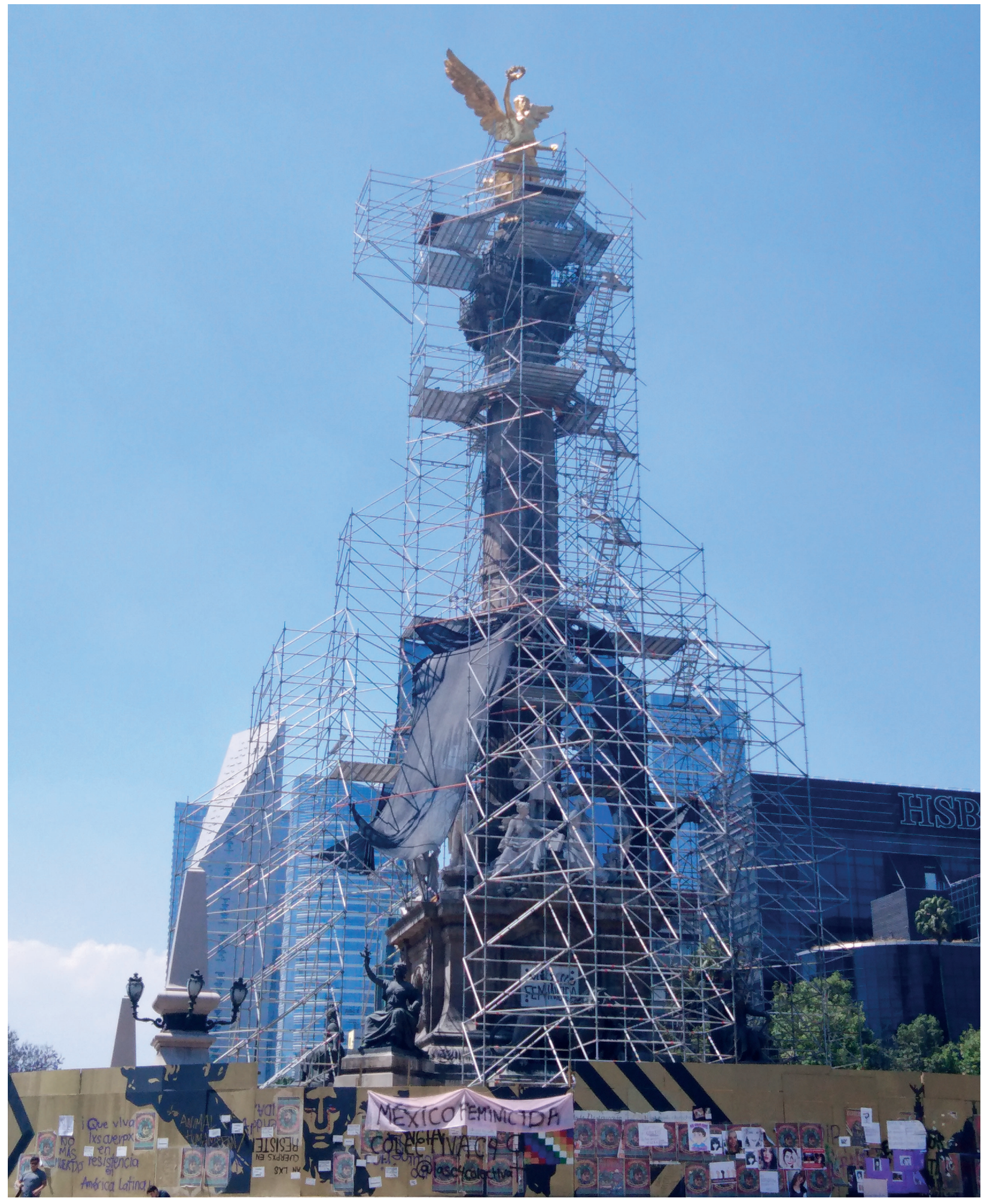

Figura 7

Invisibilizando el

principal monumento del

Paseo de la Reforma.

Fuente: Vanessa Nagel,

Archivo Vanessa Nagel, 1

de marzo de 2020 


\section{CONCLUSIONES}

10 El lunes 9 de marzo, también en un acto inédito, se convocó a través de las redes sociales a un paro nacional de mujeres que buscó hacer patente la ausencia masiva del $40 \%$ de la fuerza laboral en el país (Beauregard, 2020).
El Día Internacional de la Mujer - y con la inmediatez de la pandemia por el Covid- 19 en México- el pasado 8 de marzo de 2020 ochenta mil mujeres tomaron las calles en la capital del país. Las demandas son las mismas — rechazo a todo tipo de violencia machista, igualdad de oportunidades y la despenalización del aborto en todo el territorio nacional-, el ánimo mantiene una festiva, necesaria reivindicación (La Jornada, 2020; El País, 2020). En un acto sin precedentes, el Gobierno mexicano se pronunció a favor de las movilizaciones convocadas para el 8 y el 9 de marzo..$^{10}$ Las secretarias de Estado —encabezadas por Olga Sánchez Cordero, Secretaria de Gobernación y primera mujer en México en ocupar ese cargo- reconocieron como legítimas las demandas.

Así, la capital del país se reconoce como un espacio de construcción de ciudadanía, plataforma de aproximación social que ha propiciado la ampliación de los derechos políticos, civiles, sociales y culturales de México (Ramírez, 20I4). El Paseo de la Reforma se caracteriza por ser un espacio estratégico para la puesta en marcha de cambios trascendentales para la sociedad, como los encabezados por los colectivos feministas, puestos en la mesa de debate de la opinión pública.

En la Ciudad de México, la conquista por el derecho a manifestarse en las calles ha sido duradera. La diversificación de las demandas, primero centradas en luchas sociales y gremiales, después en libertades universales, pasando por la euforia de las victorias mundialistas mientras el país se sumía en una profunda crisis económica, hasta alcanzar las propias de la lucha por la igualdad de género, el espacio público se mantiene como el protagonista de las crónicas diarias. Por unos días, por lo menos. La inevitable crisis sanitaria por el Covid-19 en México augura varias semanas de recogimiento. Así será hasta que salgamos de nuevo a la calle a reconquistar los espacios ganados con el esfuerzo constante de varias generaciones precedentes. 


\section{REFERENCIAS BIBLIOGRÁFICAS}

AVILÉS, J. Y VELÁZQUEZ, M. (1986). Desórdenes y vandalismo invadieron la ciudad. La Jornada, (4 de junio de 1986), p. 24.

BEAUREGARD, L. (2020). México afronta un histórico paro de mujeres después de la abrumadora marcha del 8M. El País (9 de marzo de 2020). Recuperado de https://elpais.com/sociedad/2020-03-09/mexico-afronta-un-historico-paro-de-mujeres-despues-de-la-abrumadora-marcha-del-8m.html

BRAVO, E. (2019). Convierten en furia protesta contra la violencia hacia las mujeres. La Jornada (17 de agosto de 2019), p. 20.

CHEIX, V. (1986). Luchar hasta el desmayo, la consigna de México ante los belgas. La Jornada (3 de junio de 1986), p. V.

Código. Arte - Arquitectura - Diseño. (2019). Restauradoras toman postura frente a las pintas en el Ángel durante la marcha \#NoMeCuidanMeViolan. (22 de agosto de 2019). Recuperado de https://revistacodigo.com/arquitectura/ restauradoras-glitter-carta/).

El Imparcial. (1913a). Hoy celebrarán el Día del Trabajo todos los obreros de México y las Prefecturas. (1 de mayo de 1913), p. 1.

El Imparcial. (1913b). Ni odio por razas, ni división por credos. (2 de mayo de 1913), p. 5.

El País. (2020). Las mujeres mexicanas exhiben su fuerza y desbordan las calles de la capital en una marcha histórica. (9 de marzo de 2020). Recuperado de https://elpais.com/sociedad/2020-03-08/las-mujeres-mexicanas-exhiben-su-fuerza-y-desbordan-las-calles-de-la-capital-en-una-marcha-historica.html

GALAZ, L. (1986a). Versión de que México solicitó nuevas pláticas con sus acreedores. La Jornada (7 de junio de 1986), p. 1.

GALAZ, L. (1986b). La deuda externa mexicana, en un punto explosivo: Washington Post. La Jornada, (9 de junio de 1986). p. 1.

GALAZ, L. (1986c). México atraviesa la crisis más profunda en los últimos 50 años. La Jornada (23 de junio de 1986), p. 11.

GARAVITO, E. (2018). Los caminos libertarios del 68. En Relatos e Historias en México. Año XI (121), pp. 38-55.

GÓMEZ, L. (2019). Por hartazgo, las protestas contra la violencia de género. La Jornada (25 de noviembre de 2019), p. 34.

GONZÁLEZ, R. (2019). Daños ascienden a millón y medio en Metro y Metrobús; el Ángel, sin avalúo. La Jornada (18 de agosto de 2019), p. 27.

HERNÁNDEZ, E. (2018). CDMX tiene más de 2 mil marchas al año. El Universal (4 de julio de 2018). Recuperado de https://www.eluniversal.com.mx/metropoli/cdmx/cdmx-tiene-mas-de-2-mil-marchas-al-ano.

JACOB, S. (1986). No se descarta la suspensión de pagos de la deuda: Silva Herzog. La Jornada (6 de junio de 1986), p. 1.

JUÁREZ, B. (2016). Estamos hartas de la violencia machista. La Jornada (25 de abril de 2016), p. 15.

La Jornada. (1986a). Dos mil millones de personas vieron la inauguración del Mundial 86. (1 de junio de 1986), p. 1.

La Jornada. (1986b). Los límites del desahogo. (1 de junio de 1986), p. 1 y 3.

La Jornada (1986c). México venció 2-1 a Bélgica. (4 de junio de 1986), p. 1.

La Jornada. (1986d). Violencia y fútbol. (5 de junio de 1986), p. 6

La Jornada. (1986e). 250 lesionados y 134 detenidos, saldo del desalojo en Reforma. (5 de junio de 1986), p. 24. 
La Jornada. (1986f). Negocia México ajustar los pagos de la deuda a su capacidad: MMH. (11 de junio de 1986), p. 1.

La Jornada. (1986g). México, en peligro de suspender pagos de la deuda externa: Reagan. (12 de junio de 1986), p. 1.

La Jornada. (1986h). El 4-1 no hizo perder la alegría. (22 de junio de 1986), p. 1.

La Jornada. (2019a). Derechos de las mujeres están en la ley, no en lo social: expertos. (8 de marzo de 2019), p. 31.

La Jornada. (2019b). En reclamo de sus derechos, miles de mujeres marchan en el mundo. (9 de marzo de 2019), p. 1.

La Jornada. (2019c). Indignación y furia. (17 de agosto de 2019), p. 22.

La Jornada. (2019d). Un día después de la protesta por la violencia contra las mujeres. (18 de agosto de 2019), p. 1.

La Jornada. (2019e). No a la violencia contra las mujeres. (25 de noviembre de 2019), p. 2.

La Jornada. (2020). Las mujeres toman las calles. (9 de marzo de 2020). Recuperado de https://www.jornada.com.mx/2020/03/09/opinion/002a1edi.

LARROSA, M. (1986). La revolución está en la calle. La Jornada (9 de junio de 1986), p. 7.

LOAEZA, G. (1986). Yo, el Ángel de la Independencia. La Jornada (7 de junio 1986), p. 24.

MATEOS-VEGA, M. (2019). Ningún seguro en el mundo cubre la limpieza por grafitis en inmuebles históricos o artísticos: Suárez del Real. La Jornada (26 de agosto de 2019), p. 8.

MENESES, M. Y SALANUEVA, P. (1986). Más de un millón de personas festejó en las calles el triunfo de México. La Jornada (16 de junio de 1986), p. 1.

PAOLI, F. (1986). Borrachera de fútbol, euforia y marasmo. La Jornada (12 de junio de 1986), p. 5.

PERALTA, B. (1986a). El fútbol, ¿nuestra nueva identidad? La Jornada (3 de junio de 1986), p. 19.

PERALTA, B. (1986b). El fútbol, una falsa identidad nacional: Heberto Castillo. La Jornada (12 de junio de 1986), p. 21.

PÉREZ, F. (2009). Nueve semanas y media. El movimiento estudiantil de 1968. Relatos e Historias en México. Año II (14), pp. 24-33.

RAMíREZ, P. (2014). La reinvención de la ciudadanía desde el espacio público en la ciudad fragmentada. Interdisciplina, Vol. 2 (2), pp. 71-96. Recuperado de http://www.revistas.unam.mx/index.php/inter/article/view/46525/41777

RAMíREZ, P. (2015). Espacio público, ¿espacio de todos? Reflexiones desde la ciudad de México. Revista mexicana de sociología. Vol. 77 (1). Recuperado de http://www.scielo.org.mx/scielo.php?script=sci_arttext\&pi$d=S 0188-25032015000100001$.

UREÑA, J. (1986). Se estudia la suspensión de pagos, confirmó Silva Herzog. La Jornada (8 de junio de 1986), p. 1.

VARGAS, A. (2019). Instituto de la UNAM evaluará los daños del Ángel de la Independencia por sismos de 2017. La Jornada (3 de septiembre de 2019), p. 6.

VELÁZQUEZ, M. (1986). Fanáticos. La Jornada (1 de junio de 1986), p. 5.

XANTOMILA, J. (2019). En CDMX afloran diferencias entre contingentes. La Jornada (9 de marzo de 2019), p. 3. 